\title{
Movilidad y encierro "Sur-Sur": reflexiones sobre la práctica de performance participativa como investigación en la penitenciaria femenina de Santiago, Chile*
}

"South-South" Mobility and Enclosure: Reflections on a participatory practice-as-research project in the female penitentiary of Santiago, Chile

Mobilidade e confinamento "Sul-Sul": reflexões sobre a prática do performance participativo como pesquisa na prisão feminina de Santiago, Chile 


\section{Sarah Ashford Hart***}

Ph.D. Candidate, Graduate Group Performance Studies, University of California Davis

Correo electrónico: sahart@ucdavis.edu

Revista Corpo-grafías: Estudios críticos de y desde los cuerpos / Volumen 6 - Número 6 / Enero - diciembre de 2019 / ISSN impreso 2390-0288, ISSN digital 2590-9398 / Bogotá, D.C., Colombia / 214-226.

Fecha de recepción: 9 de julio de 2018

Fecha de aceptación: 10 de septiembre de 2018

Doi: https://doi.org/10.14483/25909398.14242

Cómo citar este artículo: Ashford H, S. (2019, enero-diciembre). Movilidad y encierro "Sur-Sur": reflexiones sobre la práctica de performance participativa como investigación en la penitenciaria femenina de Santiago, Chile. Revista Corpo-grafías: Estudios críticos de y desde los cuerpos, 6(6), 214-226 / ISSN 2390-0288.

*Artículo de investigación: Un proyecto de práctica-artística-como-investigación que llevé a cabo en Santiago de Chile. Junto a artistas locales, realizamos talleres con mujeres migrantes, encarceladas, de Colombia, Perú, y Bolivia. El enfoque fue el desarrollo colaborativo de una metodología para facilitar la performance participativa.

A participatory practice-as-research project initiated in Santiago, Chile, engaging incarcerated, migrant women (from Colombia, Peru, and Bolivia) in workshops with a team of local artists. The focus was the collaborative development of a methodology for facilitating participatory performance.

**A socially-engaged performance practitioner and scholar from a Canadian-Venezuelan-American family background. Her constant motivation is exploring techniques for creative exchange across barriers of difference. She has developed a unique approach to facilitating reflection on identity and belonging, with projects in the UK, Caracas, and Chile. Sarah has taught at various Chilean universities, and is currently Associate Instructor in Theatre and Dance at UC Davis. She is also Guest Editor of volume 12 of Brújula, on Performance in Latin America. Sarah has degrees from Columbia University (BA), and Dartington College of Arts (MA). Her PhD in Performance Studies takes a practice-as-research approach to developing a participatory methodology for the self-expression of experiences of mobility and enclosure. Engaging incarcerated, indigenous and migrant women in California and Chile as protagonists in artistic/academic dialogues, Sarah's work maps ethical guidelines to the intersections between self and other, performer and audience, participant and facilitator.

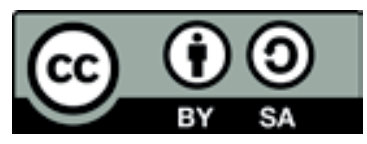




\section{Resumen}

En este ensayo, reflexiono sobre un proyecto de práctica-artística-como-investigación que llevé a cabo en Santiago de Chile. Junto a artistas locales, realizamos talleres con mujeres migrantes, encarceladas, de Colombia, Perú, y Bolivia. El enfoque fue el desarrollo colaborativo de una metodología para facilitar la performance participativa. Más allá de la narrativa representacional, logramos crear un 'espacio de afecto' potenciando así las redes del cuidado. Esta intervención creativa en las condiciones carcelarias de aislamiento y deshumanización nos permitió sentir agudamente como la autoexpresión de experiencias de movilidad y encierro puede afirmar la humanidad como condición inalienable de interdependencia. Con el presente ensayo, planteo un acercamiento, adaptable y reflexivo, a la performance participativa en contextos de la encarcelación de migrantes, tanto en Chile como otros lugares. Como parte de mi praxis de hacer-pensando, posiciono mi voz en diálogo con las perspectivas de mis colaboradoras, reconociendo a las participantes como creadoras de conocimiento. Abordo el marco teórico y el proceso de desarrollar una metodología de manera conjunta, indagando en los desafíos que enfrentamos y las nuevas preguntas emergentes.

\section{Palabras clave: movilidad; encierro; afecto; performance participativa.}




\section{Abstract}

In this essay, I reflect on a participatory practice-as-research project I initiated in Santiago, Chile, engaging incarcerated, migrant women (from Colombia, Peru, and Bolivia) in workshops with a team of local artists. The focus was the collaborative development of a methodology for facilitating participatory performance. By moving past representational narratives to embodied knowledge, we created a space of afecto, that potentiated networks of care. With this creative intervention into the isolating, dehumanizing circumstances of incarceration, we felt how the self-expression of experience of mobility and enclosure can re-affirm humanity as a condition of inalienable interdependence. With this paper, I propose a reflexive, adaptable approach to facilitating participatory performance in contexts of migrant incarceration, in Chile or elsewhere. I attempt to place my voice in dialogue with my collaborators', as part of a thinking-doing praxis, that acknowledges participants as knowledge-makers. I unpack the framework and process of developing our collaborative methodology, as well as challenges that arose and new questions that emerged.

Keywords: mobility; enclosure; affect; participatory performance.

\section{Resumo}

Neste ensaio, reflito sobre um projeto de prática artística-como-pesquisa que realizei em Santiago do Chile. Junto com artistas locais, realizamos workshops com mulheres migrantes e encarceradas da Colômbia, Peru e Bolívia. O foco foi o desenvolvimento colaborativo de uma metodologia para facilitar o performance participativo. Além da narrativa representacional, conseguimos criar um "espaço de afeto", reforçando as redes de atenção. Essa intervenção criativa nas condições prisionais de isolamento e desumanização permitiu-nos sentir com intensidade como a autoexpressão de experiências de mobilidade e confinamento pode afirmar a humanidade como uma condição inalienável de interdependência. Com este ensaio, proponho uma abordagem, adaptável e reflexiva, ao performance participativo em contextos de encarceramento de migrantes, tanto no Chile como em outros lugares. Como parte de minha práxis de fazerpensando, posiciono minha voz em diálogo com as perspectivas de meus colaboradores, reconhecendo os participantes como criadores de conhecimento. Abordo o referencial teórico e o processo de desenvolvimento de uma metodologia de forma conjunta, investigando os desafios que enfrentamos e as novas questões emergentes.

\section{Palavras-chave: mobilidade; confinamento; afeto; performance participativo.}


Ser humano es hacerse humano, es producir una relación que reivindica mi humanidad reivindicando la vida del otro. (Bautista, 2017, 189).

\section{Introducción}

Reflexionaré en las siguientes páginas acerca de un proyecto de práctica-artística-como-investigación ${ }^{1}$ que realicé en la ciudad de Santiago de Chile, involucrando a mujeres migrantes encarceladas, en talleres de performance participativa, junto con artistas locales. Exploramos como la autoexpresión creativa de experiencias de movilidad y encierro ofrece vías para afirmar la humanidad. En mi condición como estadounidense, quien vivió en Chile durante varios años, me llama la atención cómo el estado chileno sigue cada vez más el ejemplo de los EE.UU, con respecto a la deshumanización de 'inmigrantes'. Quiero apuntar a posibles métodos creativos de resistencia y solidaridad. Reconozco que un texto académico es un formato limitante para poder re-articular un proceso de performance dialógica ${ }^{2}$ que trató de alejarse de estructuras nacionalistas de representación que niegan los derechos humanos de sujetos construidos como 'indeseados' en el discurso hegemónico. La palabra nunca será suficiente para expresar el conocimiento encarnado, el cual es un constituyente productivo de la condición humana (Wacquant, 2014, p12). Hay aspectos de las experiencias vividas que se escapan (y expanden) nuestra capacidad de 'nombrar' lo aprendido. En el presente ensayo, indago por las preguntas centrales hacía conceptos emergentes del encuentro creativo con mujeres migrantes encarceladas, poniéndolas en calidad de expertas, y en diálogo con otrxs teóricxs del Norte y del Sur.

1 Ésta requiere del hacer-pensando - "hacer una pausa y pensar lo que se está haciendo", para de esta manera, "hacer borrosas las divisiones institucionales establecidas entre teoría y práctica" (Nelson, 2013, 44, 19 - mi traducción).

2 Debe resistir conclusiones y mantener abierto y continuo el diálogo entre performer y texto (Conquergood, 1985, 9). 
Este proyecto se enmarca en las redes de migración Sur-Sur, las cuales forman parte de una economía del cuidado alternativo ${ }^{3}$ entre mujeres migrantes que contrarresta la racialización ${ }^{4}$ y criminalización $n^{5}$ de sus cuerpos. El modelo capitalista concibe lo humano como la persona - máscara social históricamente reservada para hombres blancos propietarios - y construye a otros como 'no humanos'. Se supone que los inmigrantes son incapaces de ser ciudadanos y que pierden su carácter moral cuando sus raíces estén cortadas; son vistos como peligrosos (Malkki, 2012, 32). La 'solución' normalizada es encarcelar a estos 'otros odiosos' (Haritaworn, 2016) para que la nación pueda globalizarse sin perder su identidad imaginada (Shamir, 2011). La verdad hegemónica se mantiene para beneficiar a los que controlan el conocimiento, proyectando subjetividades 'criminales' en cuerpos que necesitan ser castigados y disciplinados (Foucault en Hall, 1980, p49). La prisión es una extensión de la frontera, en la lógica del régimen de movilidad global ${ }^{6}$, una estructura que separa a estos cuerpos 'indeseados' del resto de la sociedad'. ¿Porque nuestro taller con migrantes encarceladas nos permitió sentir agudamente la esencia del ser humano? Aprendimos que la autoexpresión de experiencias de vida - al ser in-aislable del mundo - afirma la humanidad como condición inalienable de interdependencia. Las redes afectivas en las cuales nos movemos son inseparables de nuestros cuerpos-mente y entrecortan las estructuras de encerramiento.

\section{Contexto}

Las participantes - 15 mujeres de Perú, Colombia, y Bolivia, imputadas en una cárcel en Santiago, quienes posteriormente iban a ser sentenciadas y deportadas, o puestas en libertad - hacían referencia a la discriminación y violencia que experimentaron como minoría con menos derechos y recursos que las ciudadanas chilenas en la cárcel. La situación de los migrantes encarcelados es similar en muchos países; existen en un limbo dónde su futuro es incierto, con tiempos indeterminados de detención durante procesos legales que no son claramente comunicados

\footnotetext{
3 No me refiero a la idea normativa de la industria del cuidado que reafirma imágenes de mujeres 'cuidadoras', así limitando sus otras capacidades.

4 En Chile el racismo estructural relega un número creciente de mujeres migrantes discriminadas como 'negras' e 'indígenas' a "nichos laborales de servicios, precarios, y del sexo" (Tijoux en Freixas y Labbé, 2016), debido a "la ideología de una diferencia étnica entre "lo chileno" -supuestamente blanco, de origen europeo- y "los otros" peruanos y bolivianos -supuestamente indígenas" que hace siglos ha negado las relaciones de las poblaciones indígenas con sus territorios y patrones ancestrales de migración Sur-Sur.

5 Estereotipos populares representan a 'inmigrantes' de Perú, Bolivia y Colombia como invasores que 'les roban el trabajo a los chilenos', y como causantes del supuesto incremento en las tasas de criminalidad (Honorato, 2017). Efectivamente, la cantidad de extranjeros en Chile se ha duplicado desde 2006 , pero sólo representan un $3 \%$ de la población y aún no afectan significativamente el mercado laboral (Aguirre en Sepúlveda, 2017), mientras la delincuencia en el país se ha disminuido recientemente (Sciaraffia, 2016).

6 La estratificación de la movilidad es inherente a la globalización, la cual “se preocupa por la prevención del movimiento y el bloqueo de acceso” por medio de procesos de encierro y contención (Shamir, 2005, p199 - mi traducción).

7 En Chile, la 'privación de libertad' oficialmente niega el derecho ambulatorio - "el derecho de toda persona a trasladarse libremente de un lugar a otro" (Organización de Estados Americanos, 1969) -, pero de manera implícita, niega el derecho de libre opinión y de afiliación - "la capacidad de vivir para y en relación a otros" (Naussbaum en Garrett, 2008).
} 
ni consistentes. Chile, al ser un pequeño laboratorio del experimento Neoliberal, pone en relieve los fenómenos del régimen de movilidad global, que permite a algunos cruzar las fronteras mientras a otros $\mathrm{no}^{8}$, para que los países destinos de migrantes económicos - como Chile, debido a su rápido 'desarrollo'9 - puedan capitalizar en un suministro de labor explotable y cuerpos desechables (Mbembe, 2003). Migrantes encarcelados son puestos en un estado de excepción, su condición humana es puesta en duda, y "pueden ser sujetados a formas arbitrarias de tratamiento que serían inaceptables en el caso de los ciudadanos" (Gündogdu, 2015, 18 - mi traducción). Las mujeres ${ }^{10}$ migrantes encarceladas tienen la menor prioridad social, en una estructura racista-patriarcal-nacionalista. Se excluye y se contiene a estos cuerpos 'indeseados', cuya función es demarcar los límites de la humanidad y la pertenencia a la nación, para que de esta manera la sociedad conformada por las personas 'buenas' pueda sentir que sus derechos y libertades son mas seguros. ¿Porqué pensamos en la prisión como el destino de 'otros', desconectados de nuestras vidas (Davis, 2003)? Este proyecto nos llevó a entender la humanidad corporalmente, como la capacidad relacional de sentirse interconectadas ${ }^{11}$, desencadenando así una serie de nuevas preguntas.

¿Cómo puede la autoexpresión creativa reivindicar derechos negados por el encarcelamiento de migrantes, haciendo valer la propia humanidad?

\section{Metodología}

El objetivo principal del proyecto fue el desarrollo colaborativo de una metodología de performance participativa. Pero, ¿Qué tanta equidad es posible lograr en el contexto de la prisión? Las participantes no habían solicitado este taller. Mi condición privilegiada como artista- académica me permitió cruzar las rejas y convocar la participación en un taller de 'expresión artística'. No quería imponer ningún resultado, tal como una performance final, sino más bien permitir que los objetivos del taller y el contenido de las actividades emergieran de manera natural a lo largo del proceso colectivo. Cuando les pregunté a las participantes qué querían hacer en el taller, ellas decían: "pasar el

\footnotetext{
8 La nueva ley de migraciones, vista como un asunto de seguridad nacional, pone más barreras a la inmigración y trabajo 'legal' de la mayoría de los migrantes (salvo los 'extranjeros' deseados de países 'desarrollados'), "generando más irregularidad y más problemas de trata y tráfico de personas" (Loredo, 2017).

9 El 'desarrollo' económico de Chile - país más desigual de ingreso del OECD (OECD, 2015) - fue impulsado con políticas capitalistas impuestos bajo la dictadura (1973-1990), instalada con la intervención estadounidense, que aterrorizaba y expulsaba a gran número de sus ciudadanos.

10 Son vistas como más aberrantes que sus contrapartes masculinas (Davis, 2003, 66).

11 La humanidad también se define como "la capacidad y la necesidad de cuidar a dependientes” y seres queridos (Gündogdu, 2015, 36).
} 
tiempo haciendo algo; hacer 'conducta'12, para irme luego de este lugar y estar con mi familia". Cuando les pregunté si les interesaría compartir sus críticas al sistema penitenciario en una presentación pública, ellas dijeron que "no, porque ya todos piensan que las extranjeras reclaman demasiado". Decidimos enfocar nuestro taller en crear un espacio (más) seguro para ellas adentro de la prisión, buscando posibles estrategias que les permitieran enfrentar sus desafíos - como la imposibilidad de comunicarse con sus familias en sus países de origen - comenzado por conectarse de manera solidaria.

Un tema emergente fue la necesidad de un 'espacio de afecto' ${ }^{13}$, entendido en este trabajo como una conexión potencial de cariño, solidaridad y cuidado. Otra definición complementaria del afecto es "la somatización de una intensidad" pre-personal y pre biográfica, que "remite la capacidad biopolítica de los cuerpos afectar y ser afectados entre sí" (Berlant en Peluffo, 2016, 21-22). Descubrimos que la autoexpresión se fomenta desde las conexiones afectivas, aún cuando sean cambiables e inestables. Por medio de palabras, imágenes y movimientos, encontramos las formas de expresión con las que las participantes se conectaron más activamente, diseñando los ejercicios de acuerdo a la retroalimentación de cada sesión. Teniendo presente que el conocimiento encarnado es inarticulable, según los términos del discurso hegemónico, exploramos aproximaciones performativas, que permitieran valorar experiencias y experticias tradicionalmente excluidas de la sociedad y (la academia). Más allá de las palabras, la autoexpresión se concibió en términos del sentimiento y el movimiento, la atmósfera y el afecto.

Reflexionamos sobre como las subjetividades son marcadas por las vivencias de migrar y estar 'privada de libertad'. Problematizamos las etiquetas socialmente inscritas en el cuerpo y nos re-conocimos como seres inter-sentientes, 'desde el 'ir-siendo' en el intercambio entre nuestra 'yoidad' in-corporada desde la experiencia de la existencia personal, y los atributos fugaces de ser condición corporal plural, colectiva, social y ambiental" (Castillo en Citro et al. Eds., 2015, 125). Intentamos crear una estética de inter-acción que valorara el devenir-juntas de re-hacerse continuamente en relación a la vida toda; la porosidad y receptividad de todo ser vivo permite esta interpelación sensible, produciendo sensaciones, expresando actitudes, y generando atmósferas (Mandoki, 2006, 14-26). Sentimos como la autoexpresión provoca sentimientos envueltos en la sociabilidad y las relacionalidades precarias del cuidado; recibir una impresión también es hacer una. Como facilitadora, propuse marcos para reflexionar sobre las dinámicas de colaboración, traduciendo lo físico en lo verbal, y viceversa, para descubrir cómo comunicarnos y fortalecer la agencia creativa dentro de las limitaciones inherentes del encuentro.

\footnotetext{
12 Aquí 'conducta' se refiere a un sistema de beneficios, como salir de la prisión por un fin de semana, a cambio de cumplir las reglas y participar en actividades como talleres.

13 Según la Real Academia Española, hay dos definiciones principales del 'afecto': "1 - inclinado a alguien o algo; 2 - cada una de las pasiones del ánimo, como la ira, el amor, el odio, etc., y especialmente el amor o el cariño". (Afecto, n.d.).
} 
¿Cómo se crea un 'espacio de afecto'? Se invita al cuerpo-mente personal-colectivo a darse cuenta de su receptividad activa a las intensidades particulares que se (nos) mueven en el espacio. Co-determinamos el cómo y el porqué de nuestras inter-acciones creativas por medio de un proceso de reorientar el 'yo' hacia una felicidad a futuro, desarrollando la capacidad de responder creativamente y brindar nuevas posibilidades de florecimiento (Lear, 2007). Pero, si facilito un ejercicio con la expectativa de generar 'afectos felices' ${ }^{14} \mathrm{y}$ una participante no se siente feliz, esa persona se podría convertir en 'un problema' para el grupo - cuando en realidad el problema fue la expectativa que yo establecí. El objetivo no es necesariamente 'sentirnos felices', sino potenciar la emergencia de sentimientos solidarios (como el cariño y la dignidad). Sólo se puede facilitar las condiciones para el posible florecimiento, sin expectativas predeterminadas. La creatividad nace desde la brecha de lo desconocido - entre lo que podríamos hacer y lo que estamos haciendo. Así, paralelamente a la cotidianidad, podemos existir de otro modo en el 'espacio de afecto', el cual posibilita la movilidad inter-relacional.

¿Cómo puede la performance participativa ofrecer marcos alternativos de inter-acción, que fisuren los discursos del régimen carcelario, por medio del presenciar de manera diferente el tiempo, el espacio y la relacionalidad?

\section{Mapas corporales}

Desarrollamos una técnica de mapeo corporal, que incluye el dibujo, el diálogo, la escritura, y el teatro, desplegando así significados, lugares, memorias, y deseos. Nos enfocamos en la actividad del mapear, entendida no desde una perspectiva visual-espacial del mundo, sino como un autorretrato del conocimiento encarnado, aterrizado en las trayectorias de las participantes en relación a espacios, experiencias y seres significativos. Les invité a expresar cómo se sentían acerca de sus lugares de origen, y cómo el moverse de un lugar a otro puede ser una experiencia transformadora, que permite que el sentido de sí cambie. Les pregunté cómo podían dibujar sus obstáculos, sus cicatrices, sus apoyos, la fuente de su fuerza y cómo se imaginaban en el futuro -ubicaron estas imágenes en una parte del contorno de su cuerpo. En un ejercicio en el que respondimos físicamente a las imágenes que dibujaron, ellas decían que se sentían "despejadas", porque "[podían] mostrar lo que sentían,"; pero también notaban "mucha nostalgia", asociada a memorias sensoriales como el "olor a comida" y "el calor de su país". Las imágenes

14 El afecto anticipatorio se enseña socialmente, pero es precisamente cuando estas buscando algo que te debe hacer feliz, que podrías experimentar la desilusión, si no resulta (Ahmed en Gregg y Seigworth, 2010). 
de sus familiares se volvían dolorosas, porque "no los podían tocar". Después de imitar entre todas las posturas representadas en sus mapas corporales, ellas decían que "se sentían conectadas". Nos dimos cuenta de que las representaciones simbólicas nunca podrían evocar los sentimientos de estar realmente en casa; sin embargo, la conexión que se generó entre nosotras en el espacio ofrecía un sentido de refugio.
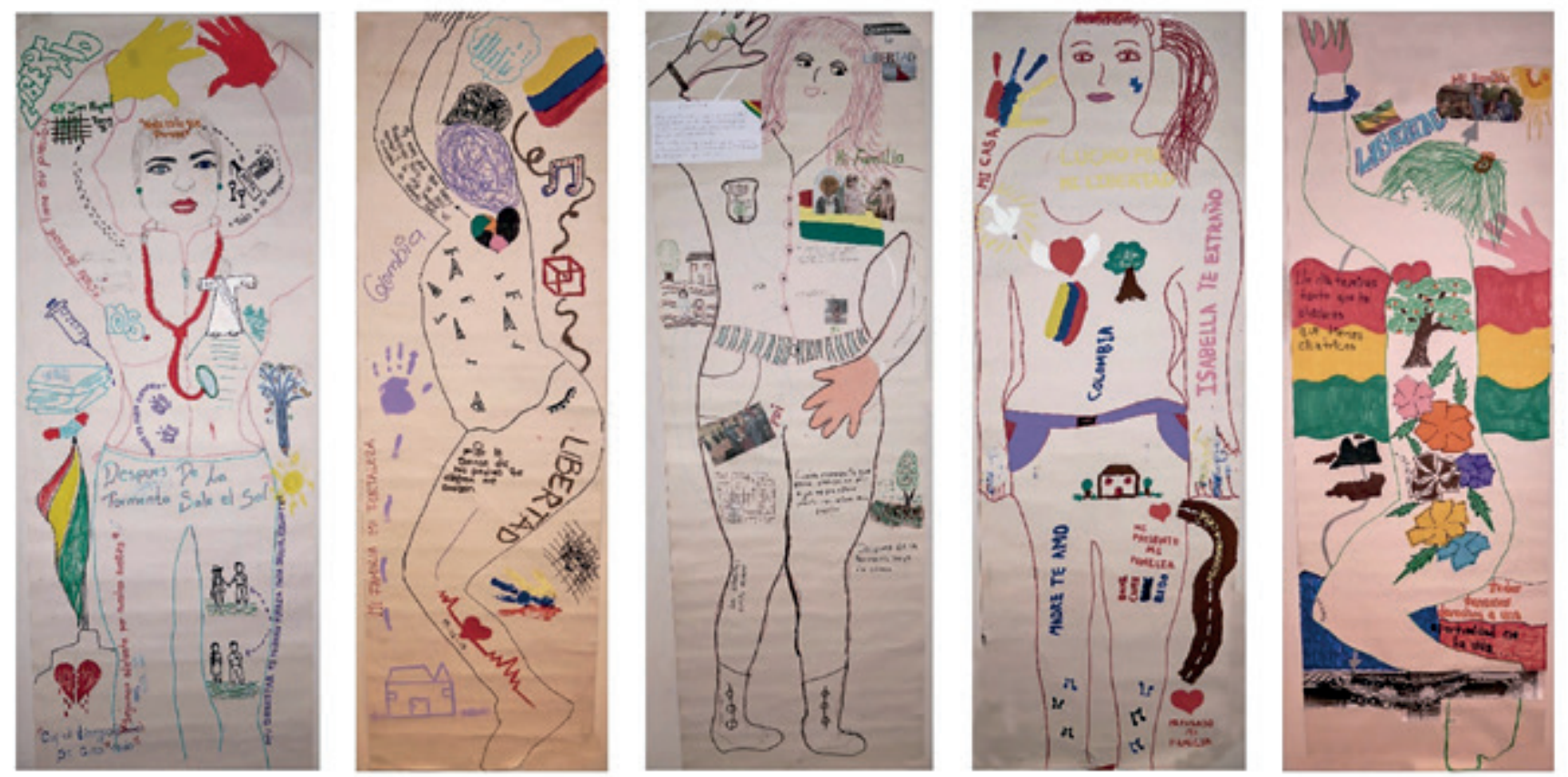

Figura 31. Mapas corporales de las participantes. Foto: Sarah A. Hart. 2017.

\section{La Libertad}

En los talleres, las participantes dijeron que se sentían 'libres', y definían la libertad como "el poder expresar libremente lo que sentimos y lo que pensamos, sin causar daño alguno." Aunque ellas sean denominadas como 'privadas de libertad', encontramos que es posible cultivar momentos y espacios de libertad al interior de la cautividad. Una de ellas expresó el siguiente mensaje: 
"Primero quiero decir cuando uno habla de libertad, habla de un derecho que tiene todo ser humano. Estando aquí siento que mi libertad está siendo cercenada, solo por ser extranjera. Estando con los míos, para mí, eso es libertad verdadera. Para mí la libertad no es salir a la calle para hacer lo que una quiere, sino estar con la familia".

La posibilidad de libre autoexpresión te puede abrir al dolor o a la felicidad, a la frustración o al alivio. Hay que hacerse vulnerable, arriesgarse a lo desconocido para poder ser transformada por el encuentro creativo. A veces, lo que resultó fructífero (o no) fue inesperado; aprendimos la importancia de responder a las particularidades del grupo -a descubrir, y a no anticipar el proceso. Decidimos compartir estas reflexiones sobre nuestro trabajo para poder alentar a otrxs aliadxs a cultivar el arte de hacer-pensando.

¿Cómo se puede resistir la deshumanización por medio de la afirmación no de la 'persona', sino de las interrelacionalidades afectivas entre todos los seres vivos?

\section{Conclusiones}

La encarcelación de migrantes intenta negar su humanidad, y se podría concluir que la libre expresión por medio de la máscara de la persona ${ }^{15}$ es el único acto de humanización posible. El teatro en la prisión puede llegar a ser instrumentalizado así por el sistema carcelario, cuando se lo integra a un programa de rehabilitación, el cual procura socializar a los ciudadanos en la forma normalizada de vivir (Balfour, 2004). Alternativamente, nuestra colaboración performativa de autoexpresión intentó contrarrestar la violación estatal del derecho de existir en la sociedad, aumentando la participación en redes del cuidado. Por medio del cuidar, "aprendemos a ser humanos" y nos conectamos a la comunidad, "practicando la interdependencia" (Brysk, 2013, 23-28-mi traducción). El 'espacio de afecto' que creamos nos sensibilizó en nuestra capacidad de afectar y ser afectadas por las interdependencias frágiles, poderosas y peligrosas que nos conectan, mas allá de la máscara de la persona. Permitimos al 'yo' transformarse y expandirse, por medio del evento de devenir-juntas - con los cuerpos, el espacio, el momento, las memorias y los sentimientos. Así descubrimos un ritmo alternativo al productivismo de la normatividad capitalista, y este cambio afectó nuestras sensaciones encarnadas y nuestro sentido del significado de la vida (Berlant, 2011).

15 Los no ciudadanos pierden acceso a dicha máscara, por medio de la cual se puede hablar y ser escuchado en la sociedad (Arendt, 1979). 
Este proyecto buscó fomentar las estrategias de sobrevivencia de las mujeres con quienes trabajamos, cultivando el bienestar no como una forma de 'reintegración social', sino una manera de trastocar el aislamiento. No pudimos cambiar las circunstancias de encarcelamiento, pero encontramos que la capacidad de resistir la deshumanización puede ser fortalecida a partir de hacer espacio y tiempo que permita explorar diferentes formas de relacionarse, como seres inter-sentientes, sin hacer caso a etiquetas peyorativas como 'criminal' e 'inmigrante'. Aprendimos que la autoexpresión de experiencias de movilidad y encierro puede aliviar (en parte) el daño causado por la encarcelación y negación de derechos, por medio de cultivar conexiones y sentimientos de solidaridad, a la vez resaltando las posibilidades y las limitaciones del cuidar y ser cuidado, revindicando así la humanidad en el hacerse interrelacionada con otras vidas.

¿Cómo puede el proceso de escribir estas reflexiones atender a las maneras en las cuales, estamos y a la vez fallamos en estar presentes una a la otra (Han, 2012)? Ya ha pasado un año y desde mi escritorio en California, espero que las mujeres con quienes trabajamos hayan salido a la libertad y estén con sus familias. La longevidad de este trabajo no se basa en mantener constantemente el 'espacio de afecto' con las mismas participantes, sino crear redes con futuros facilitadores -los artistas locales con quienes realizamos estos talleres. Estamos ahora en distintos lugares, pero no dejamos de afectarnos - formamos parte de las memorias y las trayectorias de las participantes y ellas de las nuestras. Escribo "I care"16 y siento que el proceso de pensar, escribir y leer, aunque siempre sea una reflexión parcial de lo vivido, es una parte importante de seguir afirmando nuestra capacidad de afectar y ser afectadas (Probyn, 2010). Aunque ya no nos veamos, continúo sintiendo la alegría familiar al saludarnos, la tristeza en despedirnos, y para mí, esta reverberación frágil continúa interconectándonos.

\section{Referencias}

Afecto. (n.d.) en Real Academia Española. Retirado de: http://dle.rae.es/srv/fetch?id=0wJiuAw|OwK6QI1

Ahmed, S. (2010). Happy Objects en M. Gregg, and G. Seigworth, eds. The affect theory reader. Durham and London: Duke University Press, 29-51.

Arendt, H. (1979). The origins of totalitarianism. New York: Harcourt Brace and Company.

Balfour. M. (2004). Theatre in prison: Theory and practice. Bristol: Intellect.

Bautista, R. (2017). Del mito del desarrollo al horizonte del vivir bien. Bolivia: Yo no soy si tú eres ediciones.

Berlant, L. (2011). Cruel optimisms. Durham: Duke University Press.

Brysk, A. (2013). Speaking rights to power: Constructing political will. Oxford University Press.

16 En inglés decir "I care" significa tanto importarse por cómo cuidar a alguien. 
Castillo, S. et al. (2015). El giro corporal en Colombia, en S. Citro,. et al. eds. Cuerpos y corporalidades en las culturas de las américas. Buenos Aires: Editorial Biblos, 119-150.

Conquergood, D. (1985). Performing as a Moral Act: Ethical Dimensions of the Ethnography of Performance. Literature in Performance, 5(2), 1-13.

Davis, A. (2003). Are prisons obsolete? New York: Seven Stories Press.

Freixas, M. \& Labbé, D. (2016, Abril 1). María Emilia Tijoux: El racismo está en nuestras venas, en todas. El Ciudadano. Retirado de: http:// elciudadano.com

Garcés, A. \& Guizardi, M. (2014). Historizar el Espacio: Reflexiones sobre la Construcción del Recorte Social en un Estudio sobre las Migraciones Peruanas y Bolivianas en el Norte Grande de Chile. Revista Ágora, Vitória, 19.

Garrett, J. (2008, Abril 28). Martha Nausbaum on Capibilities and Human Rights. Retirado de: https://people.wku.edu/jan.garrett/ethics/ nussbaum.htm

Gündogdu, A. (2015). Rightlessness in an age of rights: Hannah Arendt and the contemporary struggles of migrants. Oxford University Press.

Hall, S. (1997). The work of representation, en S. Hall, S. ed. Representations: Cultural representations and Signifying Practices. London: Sage and Open University, 13-64.

Han, C. (2012). Life in debt: Times of care and violence in neoliberal Chile. University of California Press.

Haritaworn, J. (2016). Queer lovers and hateful others: Regenerating violent times and places. London: Pluto Press.

Honorato, R. (2017, Agosto 28). Notas sobre la discusión migratoria. El Mostrador. Retirado de: http://www.elmostrador.cl Lear, J. (2007). Working Through the End of Civilization. International Journal of Psychology. 88(2), 291-308, DOI: 10.1516/1358-2877$55 \times 2-6888$.

Loredo, P. (2017, Agosto 24). Anuncio por Ley de Migraciones y la Situación de Hijos, Hijas de Migrantes. Revista Sur. Retirado de: http:// www.revistasur.cl

Mbembe, A (2003). Necropolitics. Public Culture. 15(1), 11-40.

Malkki, L. (1992). National Geographic: The Rooting of Peoples and the Territorialization of National Identity Among Scholars and Refugees. Cultural Anthropology, 7(1), 24-44.

Mandoki, K. (2006). Prácticas estéticas e identidades sociales. México: Siglo Veintiuno Editores.

Nelson, R. (2012). Practice as research in the arts: Principles, protocols, pedagogies, resistances. Palgrave Macmillan. Kindle Edition. Organisation for Economic Co-operation and Development, (OECD) (2015, 21 mayo). Todos Juntos ¿ Por qué reducir la desigualdad nos beneficia? ...en Chile. Retirado de www.oecd.org

Organización de los Estados Americanos. (1969) Convención Interamericana sobre Derechos Humanos. Retirado de: https://www.oas.org Peluffo, A. (2016). En clave emocional: cultura y afecto en américa latina. Buenos Aires: Prometeo libros.

Probyn, E. (2010). Writing shame, en M. Gregg, and G. Seigworth, eds. The Affect Theory Reader. London: Duke University Press, 71-90. Sciaraffia, L. (2016, diciembre 05). ¿Más delincuencia en Chile? Los datos de la percepción versus la realidad. El Definido. Retirado de https://www.eldefinido.cl

Sepúlveda, P. (2017, mayo 10). Alto porcentaje de chilenos dice que migrantes quitan trabajo. La Tercera. Retirado de: http://www2. latercera.com

Shamir, R. (2005). Without Borders? Notes on Globalization as a Mobility Regime. Sociological Theory, 23(2), $197-217$.

Wacquant, L. (2014). Homines in Extremis: What Fighting Scholars Teach us about Habitus. Body and Society, 20(2), 3-17. 